\title{
Fibras de Carbono Activadas Produzidas a Partir de Precursores Acrílicos
}

\author{
JOÃO M. VALENTE NABAIS, PETER J. M. CARROTT, MANUELA L. RIBEIRO CARROTT*
}

\begin{abstract}
Resumo
Neste artigo é efectuada uma revisão sobre as fibras de carbono activadas (ACF) produzidas a partir de precur-
\end{abstract}

sores acrílicos abordando vários aspectos relativos à sua produção e características físicas e químicas. As ACF são uma forma relativamente recente de materiais de carbono que apresentam um conjunto variado de vantagens em relação a outros materiais de carbono que Ihes conferem um enorme potencial de utilização.
As fibras de carbono são sólidos de morfologia fibrosa, geralmente de estrutura não grafítica, obtidas por carbonização de fibras orgânicas naturais, sintéticas ou procedentes de precursores orgâni$\cos$ [1]. Consoante os parâmetros sujeitos a análise assim as fibras de carbono podem ter várias classificações [1]. Por exemplo, a classificação de acordo com as propriedades mecânicas discrimina: fibras de ultra-alto módulo, fibras de alto módulo, fibras de alta força e fibras de módulo intermédio.

Contudo, a classificação mais pertinente para os nossos objectivos é a utilizada para as fibras de carbono comerciais. Esta classificação é efectuada de acordo com as aplicaçōes dos materiais e implica as seguintes classes [2]:

i) fibras de carbono de altas prestações;

ii) fibras de carbono de baixas prestações (ou de uso geral);

iii) fibras de carbono activadas.

Apesar de terem a mesma origem existe uma clara separação entre fibras de carbono e fibras de carbono activadas na medida em que os processos de produção, tal como as suas maiores aplicaçōes, são totalmente divergentes. As fibras de carbono são bastante im- portantes devido às suas propriedades físicas, nomeadamente mecânicas, e por isso encontram aplicações, quer isoladas quer na forma de compósitos, em inúmeros campos como, por exemplo, nas indústrias aeronáutica, automóvel, química e na produção de equipamentos desportivos (que pode ir desde raquetes de ténis até tacos de golfe passando por bicicletas e pranchas de surf), cirúrgicos e áudio [3,4]. Por outro lado, o interesse das fibras de carbono activadas está centrado na estrutura porosa e química que permite, como iremos mostrar mais adiante, ter aplicações nas áreas de adsorção e de catálise. Com base na classificação dos materiais de carbono recomendada pela União Internacional de Química Pura e Aplicada (IUPAC) [1] podemos dizer que as fibras de carbono activadas estão na intersecção entre carvōes activados e fibras de carbono, tal como se ilustra na figura 1.

A título de exemplo são mostradas na figura 2 duas fotografias, obtidas por microscopia electrónica de varrimento, de materiais produzidos no nosso laboratório [6].

As fibras de carbono activadas são materiais de carbono relativamente recentes que nos últimos anos têm tido um crescente interesse por parte da comu- nidade cientifica. 0 primeiro material de carbono na forma de fibra a ser produzido foi um filamento incandescente para lâmpadas por Edison e Swan em 1879. Contudo, a primeira patente registada sobre fibras de carbono activadas só apareceu em 1962 por W.F. Abbot (US patent 3,053,775). Estes materiais tiveram importantes desenvolvimentos na década de 70 onde a investigação começou em centros industriais e militares e depois se estendeu a estudos académicos, nomeadamente com a investigação de novas metodologias de produção e com a utilização de novos precursores tais como resina fenólica (Nippon Kynol Inc.), viscose (Toyobo Co.), poliacrilonitrilo (Toho Beslon Co.) e piche (Osaka Gas Co.). No anexo 1 é apresentada uma listagem das empresas que actualmente produzem fibras de carbono activadas.

As ACF podem ser produzidos na forma de fio (ou filamento), em pó ou granular com morfologia fibrosa e elevadas áreas superficiais apresentando poros estreitos e muito uniformes, regra geral em forma de fenda, cuja dimensão pode ser controlada pela escolha do precursor, ajuste das condições de produção ou por modificação do produto final. Este controlo pode ser exercido não só na estrutura porosa como também na quími-

* Centro de Química de Évora, Universidade de Évora, Departamento de Química, Rua Romão Ramalho, n. ${ }^{\circ} 59$, 7000 Évora, www.cqe.uevora.pt/gqs 
figura 1 Diagrama ilustrativo da classificação das fibras de carbono activadas dentro dos materiais de carbono (adaptado de [5])

ca superficial dos materiais. A grande maioria das fibras de carbono activadas produzidas são essencialmente microporosas ${ }^{1}$. Contudo, através da impregnação do precursor antes da activação com determinados reagentes, tais como fosfatos e ácido bórico [13], oxo-complexos de metais de transição [14], cobalto [15] ou cloreto de ferro (III) [16] podemos obter diferentes tipos de mesoporosidade. Podem também ser obtidos mesoporos por inclusão de negros de fumo no polímero de partida [17] ou por carbonização do precursor dentro de um agente estruturante como por exemplo zeólito Y [18] ou materiais de sílica mesoporosa[19].

As fibras de carbono activadas são materiais com propriedades únicas devido aos poros estarem localizados na superfície exterior da fibra de fina espessura. A sua utilização apresenta várias vantagens em relação ao uso de carvões activados em pó ou granulares $[3,5]$ :

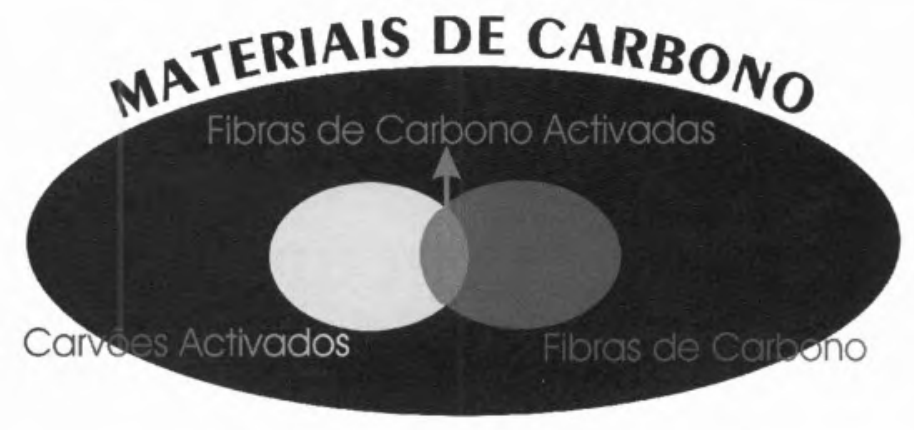

i) áreas superficiais e volumes porosos elevados;

ii) podem ser consolidadas numa vasta gama de formas como por exemplo fibras, feltros, filtros, membranas e monólitos, o que Ihes confere uma elevada versatilidade;

iii) devido a possuírem baixa resistência hidrodinâmica podem ser utilizadas no tratamento de altos fluxos de gases, o que permite uma maior flexibilidade e simplificação na sua utilização como adsorvente em processos de controlo da contaminação ambiental; além disso as suas boas propriedades mecânicas permitem operar também na presença de esforços mecânicos;

iv) a sua utilização em catálise é também bastante favorável devido à extensa dispersão de centros catalíticos e à rápida difusão dos reagentes até esses centros e subsequente remoção dos produtos da reacção; v) apresentam capacidades de adsorção e velocidades de adsorção/desadsorção mais elevadas (por vezes cerca de 100 vezes maior) do que os carvões activados.

A cinética mais favorável evidenciada pelas fibras de carbono activadas deve-se à sua estrutura fibrosa e ao facto de apresentarem microporosidade com a ausência de macroporos e em certa medida mesoporos, o que permite um contacto mais eficaz entre o adsortivo e a superfície do adsorvente. Tal como se ilustra na figura 3 a estrutura porosa apresenta diferenças nos dois casos. Enquanto que nos carvões activados a porosidade começa por apresentar macroporos que depois se ramificam em poros mais estreitos no interior do sólido, no caso das fibras de carbono activadas os microporos abrem-se directamente para o exterior permitindo ao adsortivo chegar directamente aos sítios de adsorção. Pelo contrário, no caso dos carvões activados ele tem que passar

figura 2 Fibras de carbono activadas obtidas a partir de fibras têxteis acrilicas comerciais [6].
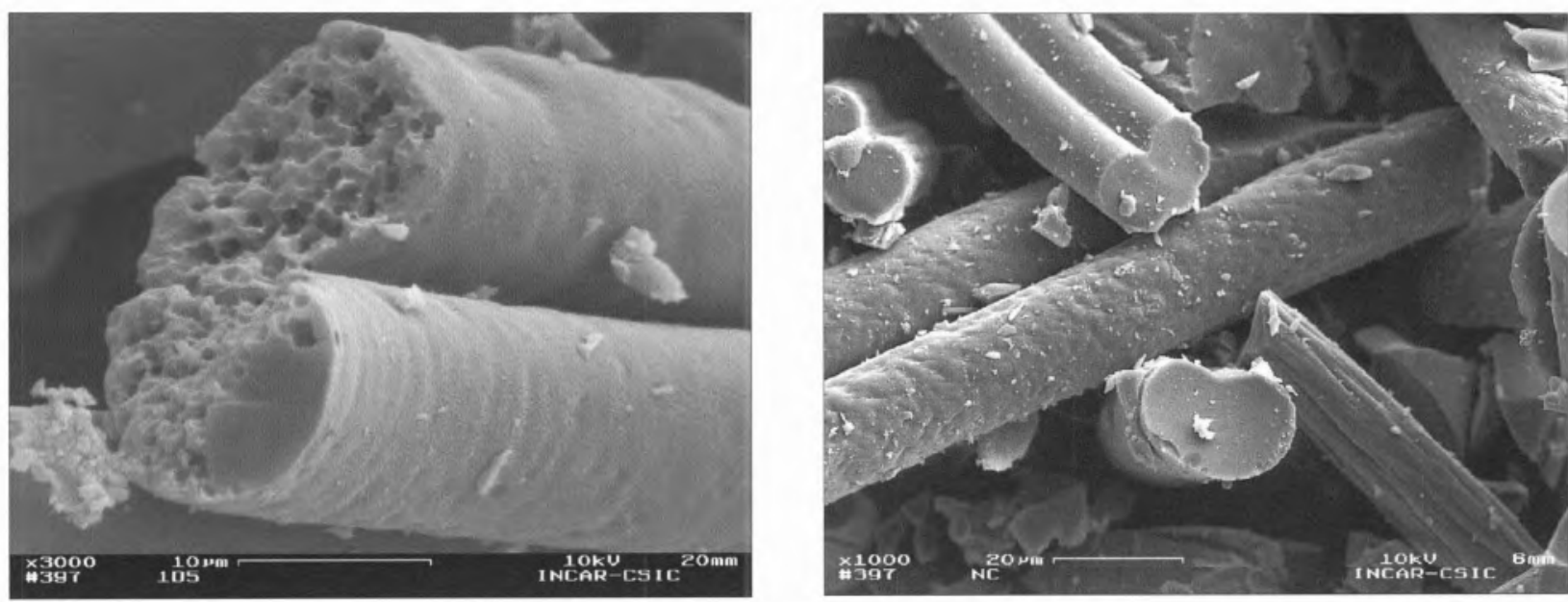


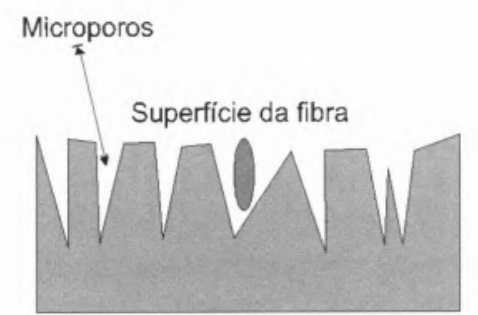

A

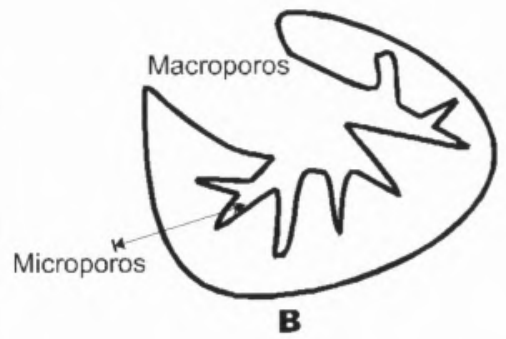

B figura 3 Representação esquemática da estrutura porosa para as fibras de carbono activadas (A) e para os carvões activados (B).

(ou activação química utilizando processos semelhantes aos usados para a produção de carvões activados). Embora os processos envolvidos na produção das fibras de carbono activadas sejam semelhantes para todos os precursores atrás citados, as reacções químicas envolvidas nestes processos, por via da natureza química desigual dos precursores, são muito diferentes e, portanto, originam também materiais de diferentes características.

O poliacrilonitrilo é o precursor mais utilizado para a produção deste tipo de materiais. A sua utilização envolve a adição de um copolímero pois quando utilizado isoladamente as reacções envolvidas na sua estabilização e carbonização são extremamente exotérmicas. Para serem produzidas fibras de carbono activadas com boas características físicas, porosas e químicas estas reacções devem ser controladas de forma a assegurar que não exista libertação súbita de calor que poderia cau-

figura 4 Adsorção de benzeno em fibras de carbono activadas e em carvões activados granulares. Cs, Ce - Concentração à saída e entrada, respectivamente. 
figura 5 Esquema da produção de fibras de carbono activadas.

sar perda de massa excessiva, quebra da cadeia do polímero ou até fusão e queima da fibra.

A presença do copolímero no precursor tem uma grande importância, pois permite não só baixar a energia libertada nestas reacçōes como também actuar como catalisador das mesmas, aumentando a sua velocidade. Kakida e Tashiro $[33,34]$ provaram que a presença do copolímero ácido 2-metilacrílico permite baixar a temperatura inicial das reacções envolvidas na estabilização da estrutura acelerando a desidrogenação e ciclização da mesma. 0 efeito do copolímero é dependente da sua natureza química e concentraçăo no precursor. Por exemplo, Sivy e Coleman [35] estudaram por espectroscopia de infravermelho com transformadas de Fourier a degradação térmica a $200^{\circ} \mathrm{C}$ sob pressão reduzida $(6,67 \mathrm{~Pa})$ do homopolímero poliacrilonitrilo e de vários copolímeros tendo concluído que a velocidade de degradação varia na seguinte ordem: poliacrilonitrilo < poli(acrilonitrilo-acetato de vinilo) < poli(acrilonitrilo-acrilamida) poli(acrilonitrilo-ácido 2-metilacrílico). Num outro estudo [36] utilizaram o precursor poli(acrilonitrilo-acrilamida) para provar que esta velocidade aumenta com o aumento da concentração de copolímero até atingir um valor limite.

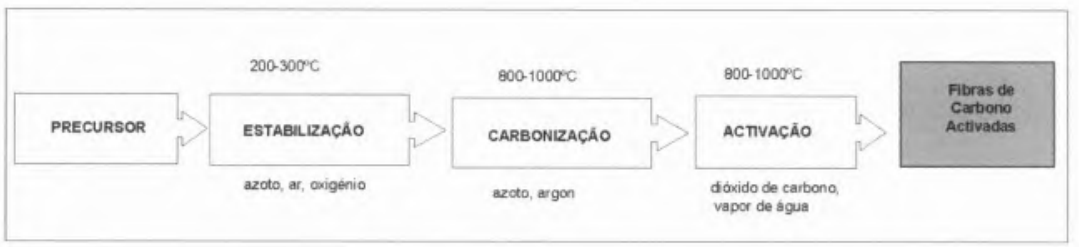

Desde a década de 50 até aos nossos dias têm sido publicados vários estudos sobre as reacções envolvidas na estabilização de precursores acrílicos, nomeadamente na produção de fibras de carbono. Contudo, os mecanismos que foram sendo propostos ao longo dos anos não tiveram o consenso da comunidade científica causando mesmo alguma controvérsia. Nos últimos anos, com o evoluir das técnicas de análise, têm surgido mais evidências que levam a um maior consenso em torno da conclusão de que as reaç̧ões predominantes no processo de estabilização são a ciclização acompanhada de uma reacção de desidrogenação, como se ilustra na figura 6 , sendo ainda discutivel se estes processos ocorrem via reacçōes inter ou intramoleculares. Em 1991 Bashir [37] publicou um artigo de revisão sobre a estabilização de poliacrilonitrilo e em 1997 Gribanov e Sazanov [38] um artigo de revisão mais geral sobre a carbonização de polímeros. A partir destes artigos podemos observar que as reacções que ocorrem na estabilização podem ser divididas em quatro grupos:

i) polimerização intramolecular do grupo nitrilo com a formação de estruturas cíclicas contendo ligações $\mathrm{C}=\mathrm{N}$; ii) reacção intermolecular do grupo nitrilo formando ligações transversais;

iii) formação de ligações cruzadas através de grupos azometino;

iv) eliminação de hidrogénio levando à formação de estruturas conjugadas $\mathrm{C}=\mathrm{C}$ na cadeia polimérica, as quais entram em reacções seguintes.

A estabilização tem como objectivo essencial a modificação da estrutura química do precursor transformando o polímero de partida numa outra forma mais estável. Desta maneira é possível converter as fibras do precursor, de características termoplásticas, em compostos não termoplásticos capazes de suportar as altas temperaturas da carbonização e activação sem perder a sua forma física [5]. Isto consegue-se através da conversão da estrutura aberta do polímero de partida numa estrutura cíclica fechada que, por intermédio das reacções de desidrogenação e ciclização (esquematizadas na figura 6), passa por uma mudança de cor de branco até negro passando por amarelo e castanho. Estas reacções, como já se fez referência, são exotérmicas $(\Delta \mathrm{H}=-242,67 \mathrm{~kJ} / \mathrm{mol}$ e $-58 \mathrm{~kJ} / \mathrm{mol}$, respectivamente para o caso do poliacrilonitrilo) e, por isso, para além dos fenómenos de encolhimento da fibra e transferência de massa, está também em jogo uma transferência de calor. 0 calor

figura 6 Representação das reacções de desidrogenação e ciclização para o poliacrilonitrilo.

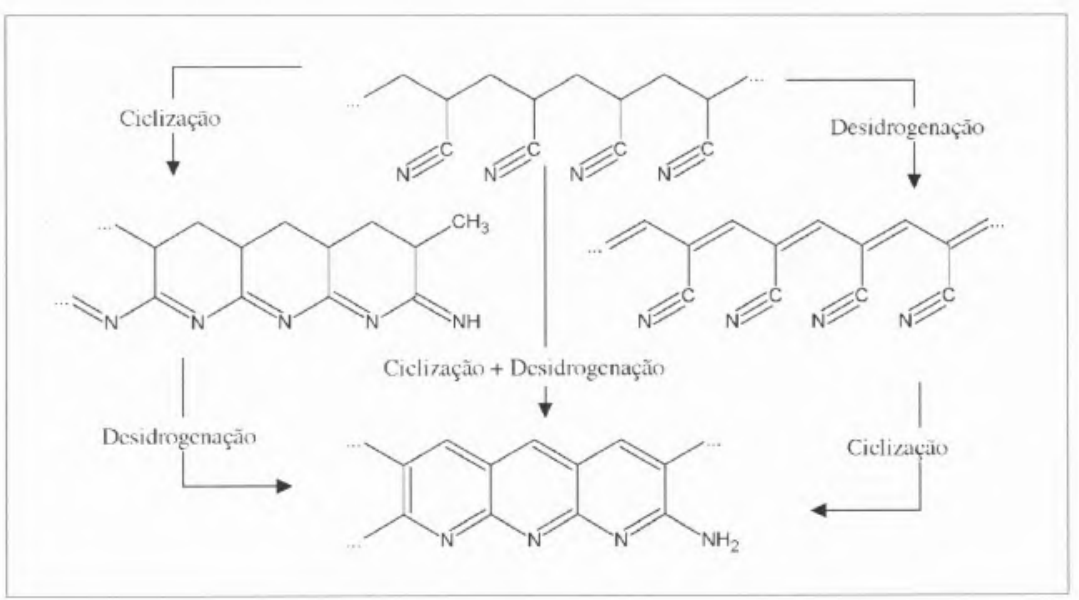




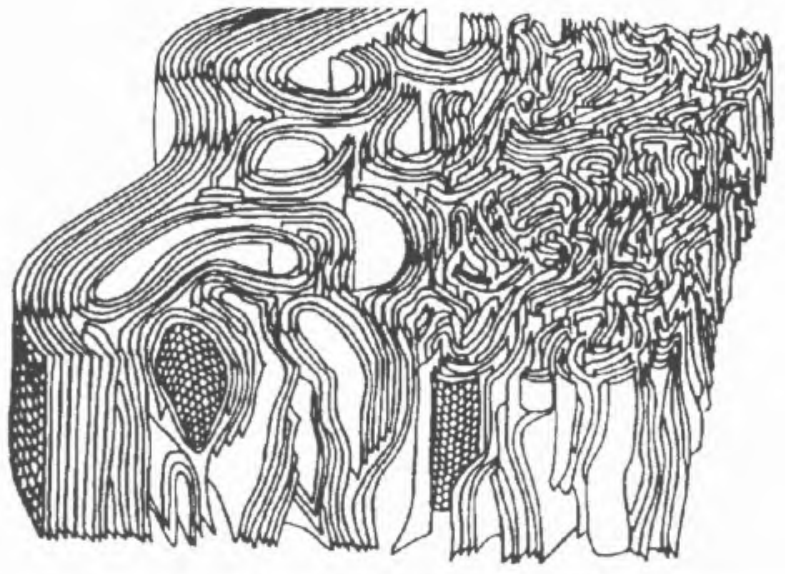

gerado durante a estabilização pode causar danos nas fibras provocando a sua quebra pois o poliacrilonitrilo é mau condutor de calor. Assim, de forma a evitar o sobre-aquecimento das fibras é necessário utilizar velocidades de aquecimento lentas, da ordem de $1^{\circ} \mathrm{C} / \mathrm{min}$. De notar que na figura 6 só está representado o uso de poliacrilonitrilo como precursor. Relembra-se que estas reacções dependem do precursor utilizado, nomeadamente do copolímero, do ambiente do processo e das condiçōes de operação do mesmo.

As fibras podem ser estabilizadas por tratamento térmico a $200-350^{\circ} \mathrm{C}$ sob fluxo de um gás oxidante (oxigénio ou ar), designada de estabilização oxidativa [36, 38] ou sob um fluxo de um gás inerte (azoto ou argon), mencionada como estabilização não oxidativa [39, 40]. Para além destes dois tipos de estabilização foram também tentados outros gases tais como amoníaco [41] e a estabilização através de bombardeamento com um feixe de electrões [42]. Contudo, os resultados mostraram não serem alternativa aos métodos anteriores.

Na comparação da estabilização oxidativa e não oxidativa, nomeadamente no que diz respeito aos parâmetros calor libertado, energia de activação, temperaturas de início e fim e mecanismo reaccional deve-se ter em consideração que eles dependem em larga medida da estrutura física e química do precursor. Contudo, de um modo geral, quando se comparam os resultados obtidos com estabilizaçāo oxidativa e não oxidativa, efectuadas sob as mesmas condições, podemos observar que, apesar de as características apresentadas pelas fibras estabilizadas serem semelhantes nos dois casos, os mecanismos para a sua obtenção são diferentes. No caso da estabilização não oxidativa a reacção de desidrogenação tem início mais cedo do que para a estabilização oxidativa, mas é mais lenta e precisa de uma temperatura maior $\left(270-300^{\circ} \mathrm{C}\right)$ para estar completa. Fitzer e Müller [43] utilizaram a análise térmica diferencial e a espectroscopia de infravermelho com transformadas de Fourier para estudar a cinética da estabilização oxidativa e não oxidativa de fibras compostas por poliacrilonitrilo e poli(acrilonitrilo-acrilato de metilo). Estes autores concluiram que a ciclização é uma reacção de primeira ordem com uma energia de activação de $125 \mathrm{~kJ} / \mathrm{mol}$ quando se utiliza um fluxo de azoto e $142 \mathrm{~kJ} / \mathrm{mol}$ para a estabilização oxidativa sob ar. A energia de activação sofre um decréscimo para $105 \mathrm{~kJ} / \mathrm{mol}$ quando está presente o copolímero. Concluiram também que o oxigénio tem duas funções antagónicas no decurso do processo, sendo por um lado um iniciador da formaçâo de centros activos para a ciclização e, por outro lado, inibe a subsequente ciclização destes centros devido ao aumento da energia de activação.

Beltz e Gustafson [44] estudaram o efeito da composição do polímero, temperatura e atmosfera utilizada na estabilizaçāo de poliacrilonitrilo e poli(acrilonitrilo-ácido itacónico), nomeadamente qual a influência destes factores na ve- figura 7 Microestrutura das fibras de carbono de alto módulo produzidas a partir de poliacrilonitrilo (adaptado de [47]).

locidade de ciclização. Este estudo foi efectuado em filmes de polímero e utilizando a espectroscopia de infravermeIho com transformadas de Fourier de forma a poder seguir as reacções presentes. Estes autores concluiram que quando a ciclização ocorre sob fluxo de azoto o polímero apresenta um período de indução seguido de um período de aceleração. À medida que a temperatura aumenta o período de indução é mais curto o que leva a uma reacção mais rápida. Na presença de oxigénio a ciclização do poliacrilonitrilo é retardada, o que significa que o oxigénio tem um efeito inibidor neste tipo de reacção que pode ser originado pelo possivel bloqueamento dos intermediários (radicais livres), não permitindo assim que a reacçāo, tal como seria necessário, se propague. Com a presença de copolimero verifica-se que esta diferença é minimizada de tal forma que para a percentagem em ácido itacónico de 3\% a ciclização sob azoto ocorre com a mesma velocidade do que sob oxigénio. A presença do copolímero vai provocar um mecanismo diferente para a ciclização em que a iniciação da reacção ocorre por um mecanismo iónico, insensivel à presença de oxigénio, no qual tomam parte os grupos ácidos do copolímero. Os autores também concluem que a presença do copolímero produz fibras mais uniformes, sem gradientes de ciclização ou porosidade.

A carbonização tem como função produzir uma extensa rede de anéis aromáticos condensados e organizados originando um produto com uma estrutura 
figura 8 Desenho esquemático das estruturas microcristalinas das fibras de carbono activadas. d002, Lc e La - parâmetros determinados por difraç̧ão de raios $\mathrm{X}$.

porosa submicroscópica pouco desenvolvida e onde na maioria dos casos os poros estão tapados por resíduos da própria carbonização. A carbonização é realizada sob um fluxo de um gás inerte, tal como argon [16] ou azoto [11, 14, $40]$, a temperaturas que vão desde os 800 até aos $1000^{\circ} \mathrm{C}$ com taxas de aquecimento de 5 e $10^{\circ} \mathrm{C} / \mathrm{min}$ e com tempos variados.

A activação vai selectivamente remover os resíduos gerando uma estrutura porosa bastante desenvolvida e formando grupos funcionais à superfície das fibras de carbono activadas. Com o aumento do tempo de activação vai aumentar também o grau de queima o que leva à obtenção de áreas superficiais maiores com aumento do volume poroso e alargamento dos microporos. Uma das técnicas mais comuns é a utilização de dióxido de carbono $[14,40]$ ou vapor de água $[10,39]$ a temperaturas entre os 800 e os $1000^{\circ} \mathrm{C}$. Embora seja referido na literatura que pode também ser usada a activação química $[4,5]$, por exemplo utilizando hidróxido de potássio [10], ácido fosfórico [45] ou cloreto de zinco [46], ela é muito pouco utilizada

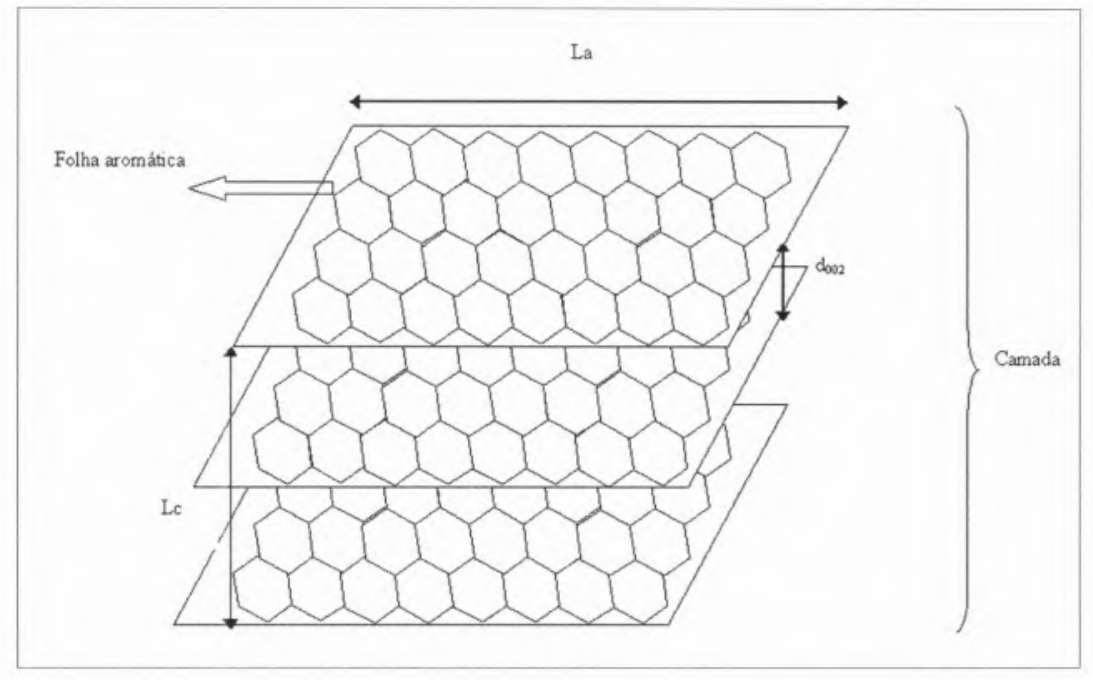

pois apresenta algumas desvantagens tais como o preço mais alto e o facto de serem produzidas fibras de carbono activadas com teor em cinzas mais elevado o que limita as possiveis aplicações para os materiais. Como vantagens a activação química apresenta maior rendimento e química superficial mais rica [4].

O método e o grau de activação influenciam as propriedades das ACF resultantes. Por exemplo, a activação com vapor de água provoca uma diminuição do diâmetro das fibras, distribuição mais larga de tamanho de poros e volumes porosos menores do que com o dióxido de carbono. Ryu e colaboradores [10] efectuaram a produção de fibras de carbono activadas a partir de poliacrilonitrilo utilizando três processos de activação com hidróxido de potássio, ar e vapor de água, tendo concluído que a activação com hidróxido de potássio apresentava área superficial e volume de poros mais elevados à custa de apresentar poros maiores (cerca de $30 \%$ dos poros estão na zona dos mesoporos) sendo a activação com ar a que apresentava menores volumes porosos e áreas superficiais. As activações com ar e vapor de água pro- duziam materiais essencialmente microporosos.

\section{Estrutura física}

É conhecido que as fibras de carbono activadas têm uma estrutura do tipo turboestrática ${ }^{2}$ originada pela libertação, durante o seu processo de produção, de pequenas moléculas tais como $\mathrm{H}_{2} \mathrm{O}$, $\mathrm{HCN}, \mathrm{NH}_{3}, \mathrm{~N}_{2}, \mathrm{CO}$ e $\mathrm{CO}_{2}$. No desenvolvimento desta estrutura os átomos de azoto e grupos funcionais presentes desempenham um papel importante pois contribuem para o desenvolvimento de defeitos locais e para o desordenamento da estrutura.

De notar que sobre a estrutura física das fibras de carbono activadas não foram ainda publicados estudos sistemáticos que permitam apresentar um diagrama desta estrutura. Contudo, para as fibras de carbono estes estudos existem e podemos, a título de exemplo, apresentar na figura 7 a estrutura das fibras de carbono de alto módulo produzidas a partir de poliacrilonitrilo, que foi proposta em 1987 por Johnson e citada por Edie [47] e Oberlin [48]. Nesta figura pode-se ver que o modelo proposto tem duas partes

\section{Tabela 1 - Resultados obtidos por difracção de raios $\mathrm{X}$ em fibras de carbono e em fibras de carbono activadas.}

Fibras de carbono[49, 50]

$\mathrm{d}_{002} / \mathrm{nm}$

$\mathrm{L}_{\mathrm{a}} / \mathrm{nm}$

$\mathrm{L}_{\mathrm{c}} / \mathrm{nm}$
$0.337-0.340$

Até 18

Até 12
Fibras de carbono activadas[12, 29]

0.350-0.372

Até 2

Até 6 


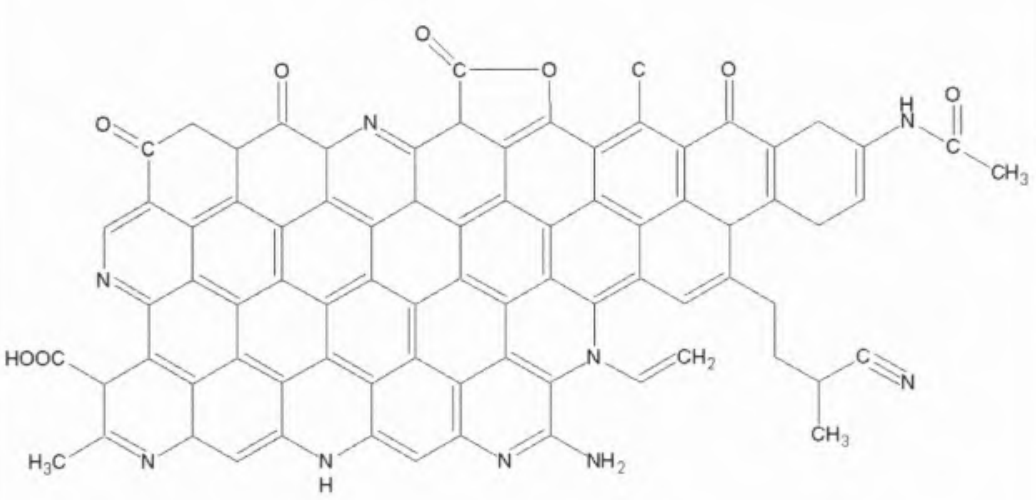

distintas. Por um lado, a zona exterior, próxima da extremidade da fibra, que apresenta uma ordenação elevada das folhas aromáticas e, por outro lado, o interior da fibra mais desordenado e com mais espaços livres. A grande diferença na produção das fibras de carbono e das fibras de carbono activadas encontra-se na última fase, onde as fibras de carbono são submetidas a grafitização a elevadas temperaturas, e que origina a elevada organização da parte exterior da fibra, enquanto que as fibras de carbono activadas são submetidas a um processo de activação, originando uma estrutura mais desorganizada do que a anterior com a formação de porosidade.

Podemos considerar que as paredes dos poros são constituídas por camadas aromáticas (conjuntos de folhas aromáticas) que a nível microscópico podem ser consideradas estruturas microcristalinas de organização semelhante à grafite, designadas por microcristalites, como se ilustra na figura 8. A estimativa da dimensão destas microcristalites pode ser obtida a partir dos dados obtidos por difracção de raios X [6,12], nomeadamente pelo cálculo do espaçamento interplanar, d002, da altura, Lc, e da largura, La, das microcristalites (figura 8). De acordo com esta analogia podemos afirmar que as fibras de carbono activadas apresentam maior quantidade de espaços ou interstícios entre as camadas aromáticas (isto é, que apresentam volumes porosos bastante mais elevados) sendo estas camadas de menores dimensões, tal como o mostram estudos de difracção de raios $X$ efectuados nestes dois tipos de materiais (tabela 1). De salientar que a natureza turboestrática das fibras de carbono activadas é caracterizada por apresentar desordem nos espaços intra e inter-microcristalites [3,4].

\section{Estrutura química}

A natureza química das fibras de carbono activadas é originada pela presença de grupos funcionais na sua superfície e é bastante importante em inúmeras aplicações destes materiais. Os grupos funcionais que normalmente estão presentes nas fibras de carbono activadas produzidas a partir de poliacrilonitrilo estão esquematizados na figura 9. Contudo, é de realçar que esta figura apenas pretende ser uma representação esquemática dos grupos mais frequentes e não um levantamento exaustivo de todos os grupos já identificados, na medida em que cada material é um caso isolado pois os grupos são formados consoante o precursor e o processo de produção utilizados.

\section{Aplicações das fibras de carbono activadas}

As fibras de carbono activadas podem ser utilizadas em inúmeras aplicações quer em fase gasosa quer em fase líquida em processos industriais ou em produtos aplicados na nossa vida diária. Das aplicações já estudadas e publicadas podemos destacar as seguintes:

- Produção de eléctrodos polarizáveis em condensadores eléctricos de dupla camada [23]. Estes aparelhos são considerados bastante promissores como ba- figura 9 Representação esquemática da quimica superficial mais comum nas fibras de carbono activadas produzidas a partir de poliacrilonitrilo e dos copolímeros mais vulgares. terias recarregáveis em virtude de, por exemplo, apresentarem uma maior velocidade de carga/descarga e uma maior densidade de energia em relação às baterias convencionais.

- Aplicações ambientais [20, 22, 25] como, por exemplo, remoção de $\mathrm{SO}_{x}$ [26] e $\mathrm{NO}_{x}$ [51]. A presença destes gases nos efluentes gasosos contribui em larga escala para a produção de chuva ácida, sendo de especial interesse a sua remoção através da utilização de materiais de carbono, nomeadamente ACF. Esta remoção pode ser realizada por adsorção ou por processos cataliticos promovidos pelos grupos funcionais presentes na superfície das ACF com a formação de, por exemplo, ácido sulfúrico a partir de dióxido de enxofre na presença de água ou pela redução selectiva dos óxidos de azoto a azoto na presença de amoníaco. As ACF são também fundamentais na adsorção de sulfureto de hidrogénio [52], hidrocarbonetos [53], chumbo (II) [54], ferro (III) [55] , cobre (II) [54], níquel (II) [54] e nitratos [56]. Importante é também a adsorção de compostos orgânicos voláteis (VOC's) [57].

- Produção de fibras de carbono activadas com propriedades antibacterianas [15] promovidas pela presença de prata finamente dispersa na superfície das ACF.

- Produção de filtros para cigarros. A capacidade de adsorção dos filtros feitos a partir de ACF é o dobro da capacidade dos filtros convencionais feitos a partir de acetato de celulose [58]. 
- Produção de ACF com propriedades catalíticas [25]. ACF dopadas com cobre mostraram ter elevada actividade catalitica na desidratação de ciclohexanol e isopropanol [59]. A impregnação com $\mathrm{Fe}\left(\mathrm{NO}_{3}\right)_{3}$ e $\mathrm{KNO}_{3}$ de $\mathrm{ACF}$ produzidas a partir de poliacrilonitrilo conduz à formação de um excelente catalisador para a sintese de amoníaco [60].

- Produção de peneiros moleculares usados para separação de gases [28] e armazenamento de metano [61] onde as fibras de carbono activadas apresentam algumas vantagens sobre os zeólitos como, por exemplo, maior selectividade, maior hidrofobicidade, maior resistência a meios ácidos e básicos e maior estabilidade térmica. Provou-se ser possível atingir elevadas selectividades e capacidade de separação dos gases para as misturas $\mathrm{CO}_{2} / \mathrm{CH}_{4}$ e $\mathrm{O}_{2} / \mathrm{N}_{2}[62,63]$ através da utilização de ACF tratadas termicamente em forno microondas.

- As aplicações na área da medicina são cada vez mais emergentes devido à aparente biocompatibilidade e grande facilidade de produção de tecidos com base nas ACF. Estes materiais podem ser utilizados como adsorvente interno tal como por exemplo o adsorvente Aqualen ${ }^{\text {TM }}$ [64], bastante útil na prevenção de cancro provocado por produtos químicos ao adsorver os produtos cancerigenos, ou na forma de tecido para tratar feridas tal como o tecido ActisorbPlus ${ }^{\text {TM }}$ comercializado em Portugal pela Johnson \& Johnson e que tem como finalidade a retençăo das bactérias e a absorção do exsudado das feridas. Uma das aplicações mais curiosas, e talvez mais bizarras, está descrita na bibliografia como substituto de pele [65]. O material em questão resulta do tratamento de ACF com plasmas dos compostos 2-hidroxietil-metacrilato, dimetil-aminoetil metacrilato e hidroximetildisiloxano.

\section{Agradecimentos}

Agradecemos à FISIPE - Fibras Sintéticas de Portugal, S.A. pela cedência dos precursores para a produção das fibras de carbono activadas e à Fundação para a Ciência e Tecnologia e ao Fundo Europeu para o Desenvolvimento Regional
(FEDER) pelo financiamento (Projecto n. ${ }^{\circ}$ PRAXIS/3/3.1/MMA/1781/95).

\section{Bibliografia}

1 - E. Fitzer, K.-H. Köchling, H.P. Boehm, H. Marsh, Pure and Applied Chemistry 67(3) (1995) 473-506.

\section{2 - A.M. Alonso, Sebenta do curso "Intro-} ducción a la Quimica y Tecnologia de Materials de Carbono", Instituto Nacional del Carbón, Oviedo, Espanha, 1999.

3 - S.-H. Yoon, Y. Korai, I. Mochida, "Carbon Fibers and Activated Carbon Fibers" em "Sciences of Carbon Materials", H. Marsh, F. Rodriguez-Reinoso (editores) Alicante, Publ. Universidade de Alicante, 2000.

4 - S. Rebouillat, J.C. Peng, J.-B. Donnet, S.-K. Ryu , "Carbon Fibers Applications" em "Carbon Fibers, 3rd Ed.', J.-B. Donnet, T.K. Wang, S. Rebouillat, J.C. Peng (editores) Nova Iorque, Marcel Dekker Inc., 2000.

5 - T. Mays, "Activated Carbon Fibers" em "Carbon Materials for Advanced Technologies", T.D. Burchell (editor) Oxford, Pergamon Press, 1999

6 - J.M. Valente Nabais, lese de Doutoramento, Universidade de Évora, 2002.

7 - K.S. Sing, D.H. Everett, R.A. Haul, L. Moscou, R.A. Pieritti, J. Rouquerol, T. Siemienewska, Pure and Applied Chemistry 57(4) (1985) 603-619.

8 - J. Rouquerol, D. Avnir, C.W. Fairbridge, D.H. Everet, J.H. Haynes, N. Pernicone, J, Ramsay, K.S. Sing, K.K. Unger, Pure and Applied Chemistry 66(8) (1994) 1739-1758.

9 - S.J. Gregg, K.S.W. Sing, "Adsorption, surface area and porosity', 2nd Ed., Academic Press Inc., Londres, 1982.

10 - Z. Rhyu, J. Zheng, M. Wang, B. Wang, Journal of Colloid and Interface Science 230 (2000) 312-319.

11 - P.J.M. Carrott, J.J. Freeman, Carbon 29(4/5) (1991) 499-506.

12 - P.J.M. Carrott, J.M.V. Nabais, M.M.L Ribeiro Carrott, J.A. Pajares, Carbon 39 (2001) 1543-1555

13 - J.B. Tomlinson, C.R. Theocharis, Carbon 30(6) (1992) 907-911.

14 - J.J. Freeman, F.G.R. Gimblett, R.A. Roberts, K.S.W. Sing, Carbon 25(4) (1987) 559-563.

15 - A. Oya, S. Yoshida, J. Alcaniz-Monge, A. Linares-Solano, Carbon 34(1) (1996)

53-57.
16 - A.W. Morawski, K. Kalucki, M. Nakashima, M. Inagaki, Carbon 32(8) (1994) 1457 1461.

17 - Y.Z. Zhang, M.Z. Wang, F. He, B.J. Zhang, Journal of Materials Science 32 (1997) 6009-6013.

18 - T. Kyotani, T. Nagai, S. Inoue, A. Tomita, Chem. Mater. 9(2) (1997) 609-615.

19 - J. Lee, S. Yoon, T. Hyeon, S.M. Oh, K.B. Kim, Chem. Commun. (1999) 2177. 2178.

20 - C. Brasquet, P. LeCloirec, Carbon 35(9) (1997) 1307-1313.

21 - Z. Li, M. Kruk, M. Jaroniec, S.-K. Ryu, Journal of Colloid and Interface Science 204 (1998) 151-156.

22 - H. Katosh, I. Kuniyoshi, M. Hirai, M. Shoda, Applied Catalysis B: Envinonmental 6 (1995) 255-262

23 - A. Yoshida, I. Tanahashi, A. Nishino, Carbon 28(5) (1990) 611-615.

24 - J. Lahaye, G. Nansé, A. Bagreev, V. Strelko, Carbon 37 (1999) 585-590.

25 - N. Shindo, Y. Otani, G. Inoue, K. Kawazoe, Desalination 98 (1994) 155-160.

26 - Y. Frei, Y.N. Sun, E. Givens, F. Derbyshire, Prep. Pap, Am. Chem. Soc., Div. Fuel Chem. 40(4) (1995) 1051-1055

27 - C.W. Jones, W.J. Koros, Carbon 32(8) (1994) 1419-1425.

28 - C.W. Jones, W.J. Koros, Carbon 32(8) (1994) 1427-1432.

29 - M.C.B. López, A. Martínez-Alonso, J.M.D. Tascón, Microporous and Mesoporous Materials 34 (2000) 171-179

30 - J.B. Tomlinson, J.J. Freeman, K.S.W. Sing, C.R. Theocharis, Carbon 33(6) (1995) 789-793.

31 - P.J.M. Carrott, J.M.V. Nabais, M.M.L. Ribeiro Carrott, J.A. Pajares, Fuel Processing Technology 77-78 (2002) 381-387

32 - P.J.M. Carrott, J.M.V. Nabais, M.M.L. Ribeiro Carrott, J.A. Menéndez, Microporous and Mesoporous Materials, 47 (2001) 243252.

33 - H. Kakida, K. Tashiro, M. Kobayashi, Polymer Journal 28(1) (1996) 30-34.

34 - H. Kakida, K. Tashiro, Polymer Journal 29(4) (1997) 353-357.

35 - M.M. Coleman, G.T. Sivy, Carbon 19 (1981) 123-126.

36 - M.M. Coleman, G.T. Sivy, P.C. Painter, R.W. Snyder, B. Gordon III, Carbon 21(3) (1983) 255-267.

37 - Z. Bashir, Carbon 29(8) (1991) 1081 1090. 
38 - A.V. Gribanov, Yu.N. Sazanov, Russian Journal of Applied Chemistry 70(6) (1997) 839-860.

39 - S.Y. You, Y.H. Park, C.R. Park, Carbon 38 (2000) 1453-1460.

40 - T.-H. Ko, P. Chiranairadul, C.-K. Lu, C.H. Lin, Carbon 30(4) (1992) 647-655.

41 - G.S. Bhat, F.L. Cook, A.S. Abhiraman, L.H. Peebles jr., Carbon 28(2/3) (1990) 377 385.

42 - J. Dietrich, P. Hirt, H. Herlinger, European Polymer Journal 32(5) (1996) 617. 623.

43 - E. Fitzer, D.J. Müller, Carbon 13(1) (1975) 63-69.

44 - L.A. Beltz, R.R. Gustafson, Carbon 34(5) (1996) 561-566.

45 - M. Jagtoyen, M. Thawites, J. Stencel, B. McEnaney, F. Derbyshire, Carbon 30(7) (1992) 1089-1096.

46 - M. Polovina, B. Babic, B. Kaluderovic, A. Dekanski, Carbon 35(8) (1997) 10471052.

47 - D.D. Edie, Carbon 36(4) (1998) 345362.

48 - A. Oberlin, S. Bonnamy, K. Ladfi, "Structure and Texture of Carbon Fibers" em "Carbon Fibers, 3rd Ed.", J.-B. Donnet, T.K. Wang, S. Rebouillat, J.C. Peng (editores) Nova lorque, Marcel Dekker Inc., 2000.

$49-\mathrm{X}$. Bourrat, "Structure in Carbons and Carbon Artifacts" em "Sciences of Carbon Materials", H. Marsh, F. Rodriguez-Reinoso (editores) Alicante, Publ. Universidade de Alicante, 2000 .

50 - B. McEnaney, "Structure and Bonding in Carbon Materials" em "Carbon Materials for Advanced Technologies", T.D. Burchell (editor) Oxford, Pergamon Press, 1999.

51 - S. Kisamori, S. Kawano, I. Mochida, Prep. Pap. Am. Chem. Soc., Div. Fuel Chem. 38(2) (1993) 421-426.

52 - J. Przepiorski, A. Oya, Journal of Materials Science Letters 17 (1998) 679-682.

53 - S.H. Li, F.M. Hsu, Ind. Eng. Chem. Res. 34 (1995) 2110-2116.

54 - K. Kadirvelu, C. Faur-Brasquet, P. Le Cloirec, Langmuir 16 (2000) 8404-8409.

55 - M. Uchida, O. Shinohara, S. Ito, N. Kawasaki, T. Nakamura, S. Tanada, Journal of Colloid and Interface Science 224 (2000) 347-350.

56 - S. Camara, Z. Wang, S. Oseki, K. Kaneko, Journal of Colloid and Interface Science 162 (1994) 520-522.

57 - M.P. Cal, M.J. Rood, S.M. Larson, Energy Fuels 11(2) (1997) 311-315.

58 - Patente Britânica 1,256,048 (1970)

59 - I.N. Ermolenko, A.M. Safonova, Z. Malashevich, G.K. Berezovik, Vestsi Akad. Navuk BSSR, Ser. Khim. Navuk 5 (1976) 17-23.

60 - A.W. Morawski, Z. Lendzion-Bielun, K. Kaluchi, R.J. Kalenczuk, Applied Catalysis: A, 156 (1997) 19-27
61 - J.A. MacDonald, D.F. Quinn, Carbon 34(9) (1996) 1103-1108.

62 - J. Angel Menéndez, P.J.M. Carrott, J.M. Valente Nabais, M.M.L. Ribeiro Carrott, Patente Espanhola P200302133 (2003)

63 - P.J.M. Carrott, J.M. Valente Nabais, M.M.L. Ribeiro Carrott, J.A. Menendez, Carbon (2003) em publicação.

64 - N.A. Vladimir, M.A. Zabezhinski, I.G. Popovich, A.I. Lieberman, J.L. Shmidt, Cancer Letters 126 (1998) 23-28.

65 - E. Piskin, A.G. Ataç, Jour. Biomed. Mater. Res. 30(4) (1996) 493-499.

\section{Notas}

1- A IUPAC [7,8] define a porosidade em relação ao diâmetro dos poros cilíndricos, ou à distância entre as paredes do poro em poros tipo fenda, da seguinte forma: $<2 \mathrm{~nm} \rightarrow$ microporos, 2-50nm $\rightarrow$ mesoporos, $>50 \mathrm{~nm} \rightarrow$ macroporos. Adicionalmente, foi proposta uma subdivisão dos microporos com base nos mecanismos primário e secundário de preenchimento de microporos [9] que tem sido aceite por vários investigadores [10-12].

2 - Em 1942 Biscoe e Warren, introduziram o conceito de ordem turboestrática como sendo constituída por grupos turboestráticos compostos por folhas de anéis aromáticos condensados aproximadamente paralelas e equidistantes entre si mas com orientação no espaço ao acaso em relação à estrutura normal da grafite (ABAB).

\section{Anexo 1}

\section{Empresa}

Actitex (PICA)

Anshan East Asia Carbon Fibers Co

Beijing Evergrow Resources Co

Calgon Carbon Co

Carbon Resources

Charcoal Cloth International

China-America Technology Co

Donau Carbon

Ekos Materials Co

Kuraray Chemical Co

Kynol

Land Industries

Noromo-HJCC Beijing

Osaka Gas Co

Taiwan Carbon Technology Co

Toho Rayon Co

Tonghui Industria \& Trading Co

Toyobo Co

Unitika

Woodville Polymer Engineering

\section{País}

França

China

China

EUA

EUA

Reino Unido

EUA

Alemanha

EUA

Japão

Japão

China

China

Japão

Taiwan

Japão

China

Japăo

Japăo

Reino Unido www.pica.fr

www.eacf.com.cn

uww.acf.ebichina.com

uww.calgoncarbon.com

www.carbonresources.com

www.chemvironcarbon.com

www.chinatech.com

www.dcffm.de/english/

www.ekos-corp.com

www.kuraraychemical.com

www.kynol.com

www.filterxport.com

www.hjcc.com.cn

www.osakagas.co.jp/indexe.htm

www.taicarbon.com.tw

www.tohotenax.com

www.china-airfilters.com

uww.toyobo.co.jp

www.unitika.co.jp

www.shamban.com 
Pอ̛̣]」ย não existe, em português, mais nenhuma obra que trate das regras gerais de "comportamento" num laboratório

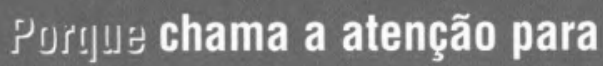
o problema da segurança nos laboratórios

Port] de tópicos essenciais que, por falta de tempo, raramente são tratados nas aulas com um nivel adequado:

- Elaboração de relatórios

- Pesquisa bibliográfica

- Aquisição automática de dados

- Análise e tratamento de dados experimentais

- Apresentação de dados em gráficos e medida de algumas propriedades

\section{GUIA DO LABORATÓRIO DE QUÍMICA E BIOQUÍMICA}

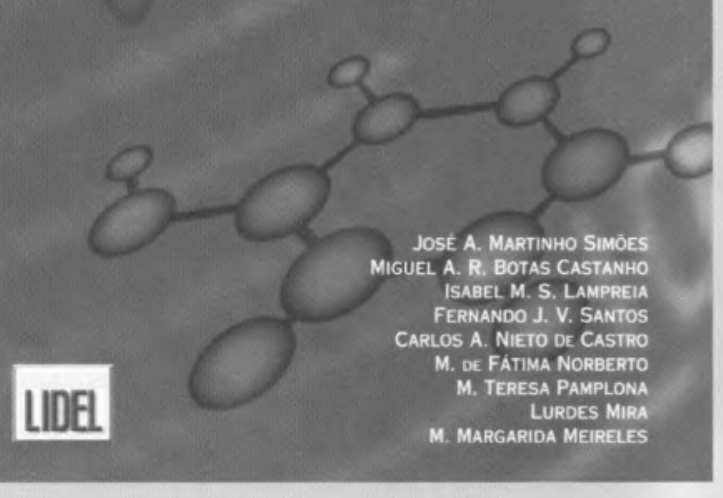

P.V.P.: $2200 \$$

Ds Direitos te Autor tesia pisa revertem a fayor da Soriedade Portuguesa te Cluíniba

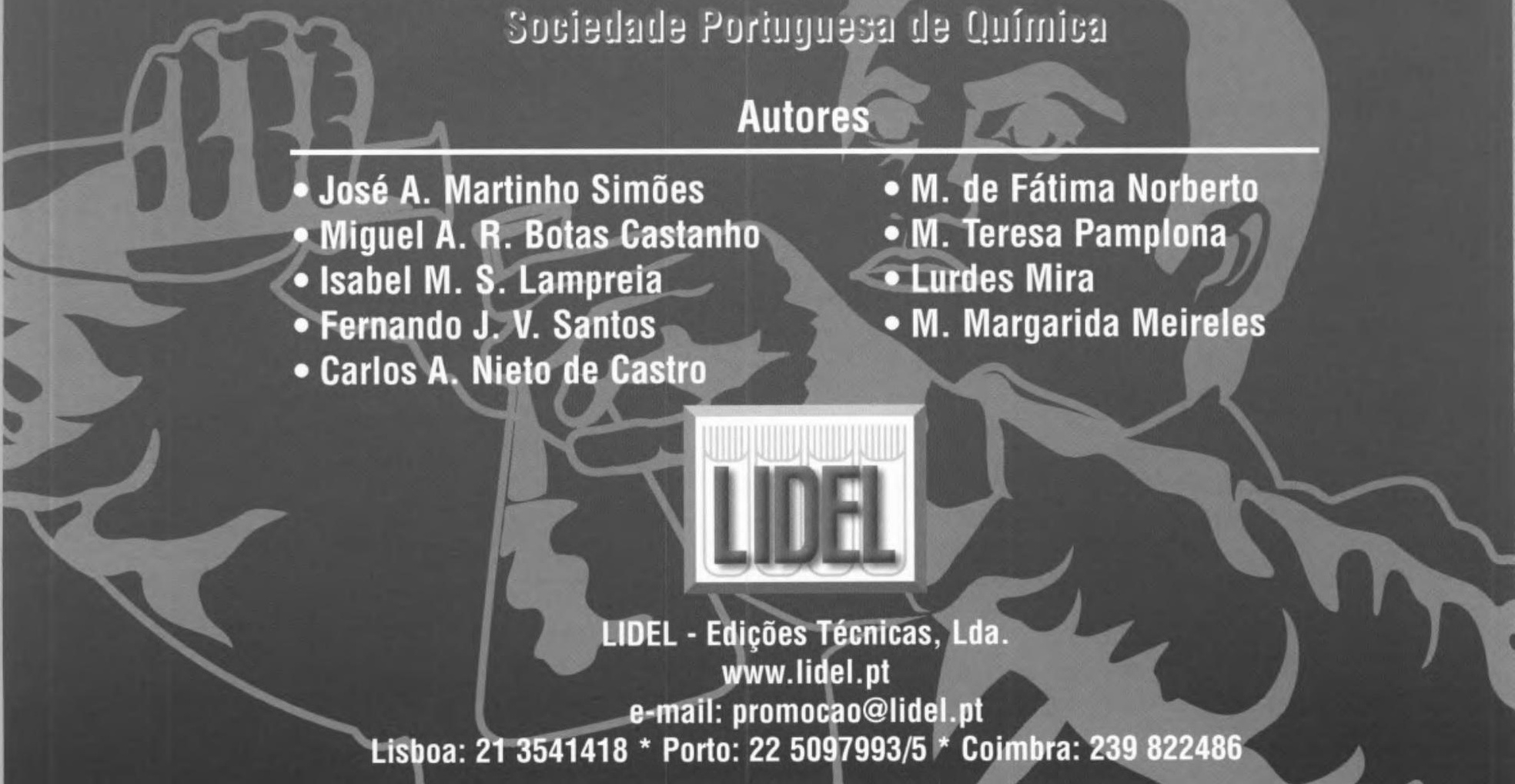

